\title{
Induction of neutralizing antibodies in mice immunized with scorpion toxins detoxified by liposomal entrapment
}

\author{
S.G. Fonseca ${ }^{1}$, \\ A.M.M. Ferreira ${ }^{1}$, \\ C.R. Diniz ${ }^{3}$ and \\ C. Chávez-Olórtegui ${ }^{2}$
}

\author{
1Departamento de Bioquímica e Imunologia, Instituto de Ciências Biológicas, \\ Universidade Federal de Minas Gerais, 31270-090 Belo Horizonte, MG, Brasil \\ ${ }^{2}$ Departamento de Patologia Básica, Setor de Ciências Biológicas, \\ Universidade Federal do Paraná, 81531-970 Curitiba, PR, Brasil \\ ${ }^{3}$ Fundação Ezequiel Dias, 30510-010 Belo Horizonte, MG, Brasil
}

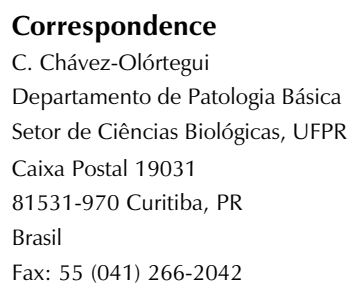

\begin{abstract}
The possibility of producing neutralizing antibodies against the lethal effects of scorpion toxins was evaluated in the mouse model by immunization with an immunogen devoid of toxicity. A toxic fraction $(5 \mathrm{mg})$ from the venom of the scorpion Tityus serrulatus was entrapped in sphingomyelin-cholesterol liposomes. The liposomes were treated for $1 \mathrm{~h}$ at $37^{\circ} \mathrm{C}$ with a $1 \%(\mathrm{w} / \mathrm{w})$ trypsin solution in $0.2 \mathrm{M}$ sodium carbonate buffer, $\mathrm{pH}$ 8.3. This treatment led to a strong reduction in venom toxicity. Immunization was performed as follows: mice were injected $s c$ with $20 \mu \mathrm{g}$ of the liposome-entrapped toxic fraction on days 1 and 21 and a final injection $(20 \mu \mathrm{g})$ was administered ip on day 36. After injection of the immunogen, all mice developed an IgG response which was shown to be specific for the toxic antigen. The antibodies were measured 10 days after the end of the immunization protocol. In an in vitro neutralization assay we observed that pre-incubation of a lethal dose of the toxic fraction with immune serum strongly reduced its toxicity. In vivo protection assays showed that mice with anti-toxin antibodies could resist the challenge with the toxic fraction, which killed, 30 min after injection, all nonimmune control mice.
\end{abstract}

Scorpion venom contains neurotoxic proteins that exert potent noxious effects on victims of scorpion stings (1). These proteins produce a complex pattern of clinical symptoms due to perturbation of the nervous, cardiovascular and respiratory systems (2). The specific medical treatment for envenomation by scorpions is the use of antisera, which are usually prepared in horses by inoculation with extracts of ground venom glands or with crude venom (3). Previous studies have shown the advantage of using the toxic fractions of Androctonus australis Hector (4) and Tityus serrulatus (5) as im-
Key words

- Liposomes

- Neutralizing antibodies

- Tityus serrulatus

- Immunization

- Toxins munogens. Therefore, the immunization of animals with such toxic substances for the production of antibodies is a serious problem. The present study reports the induction of neutralizing antibodies against Tityus serrulatus venom by immunizing mice with a non-toxic immunogen. The toxic antigen was presented to the immune system in liposomes since the physical entrapment of toxins was expected to attenuate their noxious effects and the immunoadjuvant properties of liposomes are well documented $(6,7)$.

Venoms from the mature scorpion Tityus serrulatus were provided by the Poisonous 


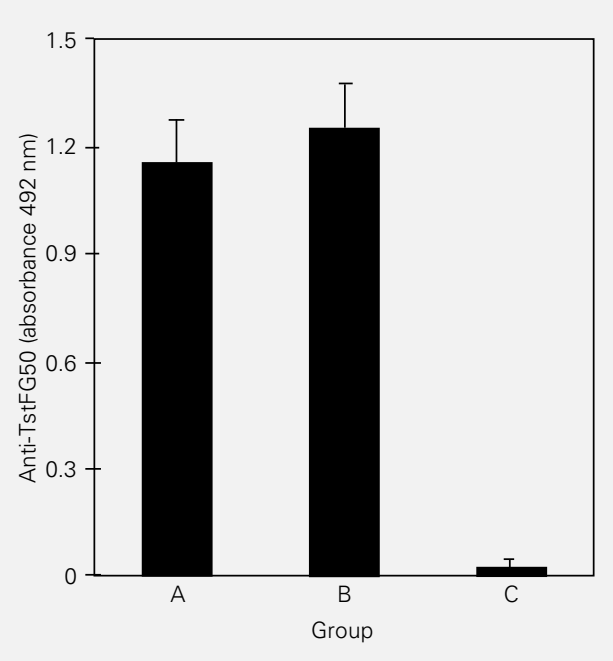

Figure 1 - Anti-TstFG50 reactivity of sera of CF1 mice immunized with liposomes. Group $A(N=15)$ mice received the TstFG50 liposomes, group $B(N=15)$ received trypsintreated TstFG50 liposomes and group $C(N=15)$ received BSA-liposomes as control. ELISA was carried out on polyvinyl microtiter plates (Hemobag Produtos Cirúrgicos Ltda., Ribeirão Preto, SP, Brazil) coated overnight with $100 \mu \mathrm{l}$ (standard volume) of a $5 \mathrm{\mu g} / \mathrm{ml}$ solution of TstFG50 in carbonate buffer, $\mathrm{pH}$ 9.6. The plates were washed with $0.05 \%$ Tween-saline (wash buffer, WB) and the blocking solution ( $2 \%$ casein in PBS) was added. The plates were incubated for $1 \mathrm{~h}$ at room temperature and washed 6 times. Mouse sera diluted $1: 100$ in dilution buffer (PBS, $0.25 \%$ casein, $0.05 \%$ Tween 20 ) were added and the plates were incubated for $1 \mathrm{~h}$ at room temperature. Peroxidase-coupled antimouse IgG (Sigma, diluted 1:1000) was added (1 $\mathrm{h}$ at room temperature). The wells were washed with WB and $100 \mu \mathrm{l}$ of an o-phenylenediamine solution $0.33 \mathrm{mg} / \mathrm{ml}$ in citrate buffer, $\mathrm{pH} 5.2$, in the presence of $0.04 \%$ hydrogen peroxide) was added. The reaction was stopped after $10 \mathrm{~min}$ by the addition of $20 \mu \mathrm{l}$ of a 1:20 dilution of sulfuric acid and absorbance was determined at $492 \mathrm{~nm}$ with a Titertek Multiscan plate spectrophotometer. All measurements were made in duplicate. Data are reported as means \pm SD.

Animal Section, Fundação Ezequiel Dias (FUNED), Belo Horizonte, Brazil. The toxic fraction of crude $T$. serrulatus venom (TstFG50) was separated by Sephadex G-50 chromatography according to Miranda et al. (8). The toxic activity of the chromatographic fractions was assayed by subcutaneous $(s c)$ injections into $\mathrm{CF} 1$ mice provided by the FUNED Animal House. After lyophilization the TstFG50 was dissolved to $5 \mathrm{mg} / \mathrm{ml}$ in phosphate-buffered saline (PBS) and used for liposome preparation, ELISA or toxicity assays. Sphingomyelin-cholesterol liposomes were prepared according to the method of
Szoka and Papahadjapoulos (9), as previously described (5). TstFG50 (5 mg/ml) was used as antigen and BSA $(5 \mathrm{mg} / \mathrm{ml})$ as control. The extent of protein incorporation was assessed by the method of Lowry et al. (10) for the determination of protein in the starting solution and in the supernatant after centrifugation of the liposomes $(1000 \mathrm{~g}$ for $20 \mathrm{~min}$ ). Liposomes prepared as above were treated for $1 \mathrm{~h}$ at $37^{\circ} \mathrm{C}$ with a $1 \%(\mathrm{w} / \mathrm{w})$ trypsin solution in $0.2 \mathrm{M}$ sodium carbonate buffer, $\mathrm{pH}$ 8.3. Before and after the enzymatic treatment, liposomes were washed by centrifugation 3 times in the digestion buffer. Liposome preparations were kept at $4^{\circ} \mathrm{C}$.

The toxicity of liposome preparations was assayed using naive $\mathrm{CF} 1$ mice ( 4 animals per group), which received $s c$ injections of PBS containing increasing quantities of liposomes and $1 \mathrm{mg}$ aluminum hydroxide. Incorporation of TstFG50 into sphingomyelin-cholesterol liposomes, a method derived from phase evaporation (6), was an efficient procedure for the reduction of initial toxicity of this antigen to five times its initial value. The quantity of liposome-entrapped TstFG50 equivalent to $3 \mathrm{LD}_{50}(20 \mu \mathrm{g})$ could be administered to naive $\mathrm{CF} 1$ mice without killing the animals. In an attempt to improve the detoxification procedure, TstFG50 liposomes were also treated with trypsin. The resulting trypsin-treated liposomes were devoid of any measurable toxicity, i.e., it was not possible to elicit poisoning symptoms at doses equivalent to $20 \mathrm{LD}_{50}=130 \mu \mathrm{g}$ of TstFG50, consistent with the possibility that some externally adsorbed toxin had contributed to the toxicity of the initial standard preparation of TstFG50 liposomes. Similar or even better detoxification levels have been reported by New et al. (6) using snake venom as antigen.

The ability of these liposome preparations to elicit a protective immune response was evaluated in mice. Immunization was performed as follows: after collection of preimmune sera by retroorbital puncture, a group of 15 CF1 mice (group A) were injected $s c$ 
with $20 \mu \mathrm{g}$ of the liposome-entrapped toxic fraction in $1 \mathrm{mg}$ aluminum hydroxide (day 1). Similar booster injections were administered 21 days later. The final injection (20 $\mu \mathrm{g})$ was administered intraperitoneally on day 36. Mice of group B received trypsintreated liposomes containing $20 \mu \mathrm{g}$ of the TstFG50 antigen, using the same protocol as above. The control group (group C) received liposome-entrapped BSA (20 $\mu \mathrm{g}$ per injection). Immune sera were collected on day 46. When the sera of mice subjected to the immunization protocol were analyzed by ELISA for their reactivity towards the TstFG50 fraction (Figure 1), it was apparent that each mouse serum (groups A and B) displayed consistent immunoreactivity with the TstFG50 fraction added to the microtiter plate, while sera from control mice did not react.

Finally, the capacity of circulating antibodies of immunized mice to neutralize TstFG50 was determined both in vitro and in vivo. For in vitro neutralization assays, preincubation $\left(1 \mathrm{~h}\right.$ at $\left.37^{\circ} \mathrm{C}\right)$ of three $\mathrm{LD}_{50}$ of the TstFG50 with a pool of $50 \mu \mathrm{l}$ immune sera from group $\mathrm{A}\left(\mathrm{N}=4\right.$, mean $\left.\mathrm{A}_{492 \mathrm{~nm}}=1.179\right)$, group $\mathrm{B}\left(\mathrm{N}=4\right.$, mean $\left.\mathrm{A}_{492 \mathrm{~nm}}=1.103\right)$ or group $\mathrm{C}$ (control) followed by injection into naive CF1 mice (four animals per group) considerably reduced the toxicity of the toxic fraction. In group A all mice survived and $50 \%$ of group B survived the same dose. This observation was confirmed by in vivo experiments in which immunized mice resisted a sc challenge with TstFG50. The results of these experiments are reported in Table 1. Mice from groups A and B fully resisted injection of $3 \mathrm{LD}_{50}$ of the toxic fraction. In group A all mice survived a challenge of $10 \mathrm{LD}_{50}$ and only one mouse from group $B$ died with the same dose. However, only half of group A and B mice survived the high dose of $15 \mathrm{LD}_{50}$. To better appreciate the efficacy of this protection, it should be remembered that the average amount of venom that one Tityus serrulatus
Table 1 - In vivo protection experiments.

Groups of four mice from the three immunization groups received subcutaneously $3 L_{50}$ (experiment 1), $10 L D_{50}$ (experiment 2) or $15 L_{50}$ (experiment 3) of TstFG50, 10 days after the third immunization. Group A had been immunized with TstFG50 liposomes and group B with trypsintreated TstFG50 liposomes. Control groups (C) had been immunized with BSA liposomes. AntiTstFG50 antibodies were measured in individual mice and are reported as the average of four ELISA determinations. The mice were grouped randomly. Surviving mice were counted $24 \mathrm{~h}$ after injection. The $L_{50}$ of the TstFG50 used throughout the study was $6.5 \mu \mathrm{g}$ per $20 \mathrm{~g}$ mouse (sc injection into CF1 mice).

\begin{tabular}{llcc}
\hline Experiment & Mice & $\begin{array}{c}\text { Anti-TstFG50 } \\
\text { antibodies } \\
\left(\mathrm{A}_{492 \mathrm{~nm}}\right)\end{array}$ & $\begin{array}{c}\text { Surviving } \\
\text { mice }\end{array}$ \\
\hline 1 & Group A & 1.187 & $4 / 4$ \\
2 & Group B & 1.121 & $4 / 4$ \\
& Group C & 0.020 & $0 / 0$ \\
3 & Group A & 1.171 & $4 / 4$ \\
& Group B & 1.177 & $3 / 4$ \\
& Group C & 0.007 & $0 / 4$ \\
& Group A & 1.177 & $2 / 4$ \\
& Group B & 1.180 & $2 / 4$ \\
& Group C & 0.025 & $0 / 4$
\end{tabular}

scorpion delivers under laboratory conditions was found to be $0.25 \pm 0.10 \mathrm{mg}$ dried venom and that the TstFG50 is approximately $45 \%$ of the whole venom. Thus, one average scorpion sting corresponds to 10-15 $\mathrm{LD}_{50}$, suggesting that immune mice probably resist a real scorpion sting.

In conclusion, these results are encouraging in that they show that protective antibodies against scorpion toxins can be elicited in laboratory animals by using an immunogenic form of the venom which was devoid of toxicity by entrapping it into liposomes and subsequent treatment with trypsin.

\section{Acknowledgments}

The authors thank Dr. Frederic Frezar and Dra. Ida C. Gubert for revising the manuscript, and Dário José de Souza for technical assistance. 


\section{References}

1. Possani LD (1984). Structure of scorpion toxins. In: Tu A (Editor), Handbook of Natural Toxins. Marcel Dekker, New York and Basel, 513-550.

2. Campos JA, Silva OS, Lopez M \& FreireMaia L (1980). Signs, symptoms and treatment of severe scorpion sting in children. In: Eaker D \& Wadstrom T (Editors), Natural Toxins. Pergamon Press, Oxford, 6162.

3. Barrio A \& Vital Brazil G (1949). Ein neues Verfahren der Giftentnahme bei Spinnen. Experientia, 6: 112-113.

4. Delori $P$, Van Rietschoten $J$ \& Rochat $H$ (1981). Scorpion venoms and neurotoxins: an immunological study. Toxicon, 19: 392-407.
5. Chávez-Olórtegui C, Ait Amara D, Rochat H, Diniz C \& Granier C (1991). In vivo protection against scorpion toxins by liposomal immunization. Vaccine, 9: 907-911.

6. New RRC, Theakston DG, Zumbuehl O, Iddon D \& Friend J (1985). Liposomal immunization against snake venoms. Toxicon, 23: 215-219.

7. Gregoriadis G (1990). Immunological adjuvants. Immunology Today, 11: 89-97.

8. Miranda F, Kopeyan C, Rochat $H$ \& Lissitzky S (1970). Purification of animal neurotoxins: isolation and characterization of eleven neurotoxins from the venoms of the scorpions Androctonus australis Hector, Buthus occitanus tunetanus and Leiurus quinquestriatus quinquestriatus. European Journal of Biochemistry, 16: 514-523.
9. Szoka F \& Papahadjapoulos D (1978). Procedure for preparation of liposomes with large internal aqueous space and high capture by reverse-phase evaporation. Proceedings of the National Academy of Sciences, USA, 75: 4194-4198.

10. Lowry $\mathrm{OH}$, Rosebrough NJ, Farr $\mathrm{AL}$ \& Randall RJ (1951). Protein measurement with the Folin phenol reagent. Journal of Biological Chemistry, 193: 265-275. 